\title{
Modeling of Quantile Regression to Know the Factors Affecting of the High Spread Api Malaria in Indonesia
}

\author{
Pemodelan Regresi Quantil untuk Mengetahui Faktor-Faktor yang \\ Mempengaruhi Tingginya Penyebaran Api Malaria di Indonesia
}

\author{
${ }^{1}$ M. Y. Matdoan, ${ }^{2}$ B. W Otok, ${ }^{3}$ R. M. Atok
}

\begin{abstract}
The OLS method estimation is based on a normal distribution, so it is not appropriate to analyze a number of data that are not symmetrical or contain outliers. Therefore, quantile regression was developed which was not affected by outliers. This study compares quantile regression with OLS in the case of factors affecting malaria in Indonesia. The results show that the value of the Quantil Regression model is 0,832 and the MSE value is 0,182. In addition, the OLS model obtained a value of 0,681 and an MSE value of 0,231 . So we get the conclusion that the best model is a quantile regression model. Further results were obtained that the main factors causing the spread of malaria in Indonesia were the factor of livable houses, poor population factors and physician factors.
\end{abstract}

Keywords : Quantile Regression, Outliers, Malaria

\begin{abstract}
Abstrak
Estimasi Metode OLS didasarkan pada distribusi normal, sehingga kurang tepat untuk menganalisis sejumlah data yang tidak simetris atau mengandung outlier. Oleh karena itu, dikembangkan regresi quantil yang tidak terpengaruh oleh adanya pencilan (outlier). Penelitian ini membandingkan regresi quantil dengan OLS pada kasus faktor-faktor yang mempengaruhi penyebaran API malaria di Indonesia. Diperoleh hasil bahwa nilai $R^{2}$ dari model Regresi Quantil sebesar 0,832 dan nilai MSE yaitu sebesar 0,182 . Selain itu, pada model OLS diperoleh nilai $R^{2}$ yaitu sebesar 0,681 dan nilai MSE yaitu sebesar 0,231 . Sehingga diperoleh kesimpulan bahwa model terbaik adalah model regresi quantil. Lebih lanjut diperoleh hasil bahwa faktor utama penyebab penyebaran penyakit malaria di Indonesia yaitu faktor rumah layak huni, faktor penduduk miskin dan faktor tenaga dokter.
\end{abstract}

Kata Kunci : Regresi Quantil, Outliers, Malaria

\section{Pendahuluan}

Analisis regresi merupakan salah satu metode statistika yang digunakan untuk menggambarkan hubungan antara dua atau lebih variabel, sehingga suatu variabel dapat ${ }^{1}$ Program Studi Statistika, Universitas Pattimura

${ }^{2,3}$ Jurusan Statistika, Institut Teknologi Sepuluh Nopember

${ }^{1}$ e-mail : keepyahya@gmail.com 
diprediksikan dari variabel yang lain [2]. Variabel yang ditaksir nilainya disebut variabel respon $(Y)$ sedangkan variabel penaksir disebut sebagai variabel prediktor $(X)$. [3]

Pendekatan standar untuk mendapatkan nilai dugaan parameter dari model regresi linier adalah metode Ordinary Least Square (OLS) [5]. Dalam analisis regresi parametrik (khususnya regresi klasik), Gujarati (2004) menyatakan bahwa ada beberapa asumsi yang harus dipenuhi dalam melakukan estimasi, yaitu tidak terjadi multikolinieritas antar variabel prediktor, tidak terjadi otokorelasi dan heteroskedastisitas, serta residual berdistribusi normal [7]. Jika semua asumsi tersebut terpenuhi, maka hasil estimasi dengan meggunakan metode OLS bersifat Best Linear Unbiased Estimator (BLUE).[8]

Estimasi parameter dengan menggunakan metode OLS diperoleh dengan meminimumkan jumlah kuadrat sisaan (residual) dan berdasarkan pada distribusi mean [9], dimana nilai mean menunjukan ukuran pemusatan dari suatu distribusi data [6]. Oleh sebab itu, pendekatan dengan menggunakan metode OLS tidak dapat merepresentasikan keseluruhan data[15]. Untuk mengatasi masalah tersebut, maka dikembangkanlah metode regresi quantil. Regresi quantil pertama kali diperkenalkan oleh Koenker dan Basset (1978), Metode ini merupakan perluasan dari model regresi pada quantil bersyarat [12]. Untuk mendapatkan estimasi parameter model regresi quantil diperoleh dengan menggunakan metode pemorograman linier diantarnya algoritma simpleks, interior-point, dan smoothing [11].

Malaria adalah penyakit infeksi yang disebabkan oleh parasit Plasmodium yang hidup dan berkembang biak dalam sel darah merah manusia, ditularkan oleh nyamuk (Anopheles) betina dan dapat menyerang semua orang, baik laki-laki maupun perempuan pada semua golongan umur dari bayi, anak-anak maupun orang dewasa [10]. Penyakit malaria secara langsung dapat menyebabkan seseorang sering sakit, daya tahan tubuh rendah serta menyebabkan kematian.

Di Indonesia penyakit malaria ditemukan tersebar luas di berbagai daerah dengan derajat infeksi yang bervariasi. Kejadian tersebut disebabkan karena adanya permasalahan-permasalahan teknis seperti pembangunan yang tidak peduli terhadap kesehatan lingkungan, mobilitas penduduk dari daerah endemis malaria, wilayah terpencil dengan kondisi lingkungan yang tidak baik dan minimnya akses pelayanan kesehatan serta kondisi ekonomi masyarakat yang rendah. Jumlah Penderita positif penyakit malaria di Indonesia pada tahun 2015 sebanyak 217.025 jiwa, Berdasarkan data dari Kementrian Kesehatan Republik Indonesia bahwa jumlah penderita penyakit malaria sudah mengalami penurunan. Namun, penurunan penderita penyakit malaria di Indonesia masih tetap harus diwaspadai, karena adanya disparitas (kesenjangan) penyebaran penyakit malaria antar daerah di Indonesia [13]. Sehingga, diduga datanya mengandung pencilan (outliers). Oleh karena itu, perlu dilakukan penelitian lebih lanjut mengenai faktor-faktor yang mempengaruhi tingginya penyebaran API malaria di Indonesia. 


\section{Metodologi Penelitian}

\section{A. Sumber Data}

Data yang digunakan dalam penelitian ini adalah data sekunder yang diperoleh dari Kementrian Kesehatan Republik Indonesia dan Badan Pusat Statistika (BPS) pada tahun 2015 [1]. Data yang diambil mengenai presentase Annual Parasite Incidence (API) malaria pada 34 Provinsi di Indonesia beserta faktor-faktor yang diduga mempengaruhi.

\section{B. Variabel Penelitian}

Variabel yang digunakan dalam penelitian ini dapat dilihat pada Tabel 1 berikut.

Tabel 1. Variabel Penelitian

\begin{tabular}{cl}
\hline Variabel & \multicolumn{1}{c}{ Keterangan } \\
\hline$Y$ & Annual parasite incidence (API) malaria \\
$X_{1}$ & Presentase akses sanitasi layak \\
$X_{2}$ & Presentase rumah layak huni \\
$X_{3}$ & Presentase penduduk miskin \\
$X_{4}$ & Rasio tenaga dokter \\
$X_{5}$ & Presentase akses air bersih \\
$X_{6}$ & Rasio puskesmas \\
\hline
\end{tabular}

\section{Hasil dan Pembahasan}

\section{A. Analisis Deskriptif dan Identifikasi Data}

Hasil statistik deskriptif pada kasus penyakit malaria dan faktor-faktor yang mempengaruhi penyebaran penyakit malaria disajikan pada Tabel 2 berkut.

Tabel 2. Statistika Deskriptif

\begin{tabular}{llcrrrrr}
\hline Deskriptif & $Y$ & $X_{1}$ & $X_{2}$ & $X_{3}$ & $X_{4}$ & $X_{5}$ & $X_{6}$ \\
\hline Mean & 2,63 & 59 & 89,8 & 11,7 & 20,1 & 68,6 & 1,86 \\
Minimum & 0 & 23,9 & 49,2 & 3,6 & 10,9 & 41,0 & 0,58 \\
Maksimum & 31,9 & 89,2 & 99,2 & 28,4 & 39,1 & 93,4 & 5,20 \\
Range & 31,9 & 65,3 & 49,9 & 24,7 & 28,2 & 52,3 & 4,62 \\
Std Dev & 7,51 & 15,3 & 10,4 & 6,1 & 6,8 & 11,0 & 1,07 \\
Variansi & 56,4 & 236 & 108,3 & 38,2 & 46,4 & 121,7 & 1,15 \\
\hline
\end{tabular}




\section{B. Identifikasi Pola Hubungan dan Pengujian Outlier}

Studi kasus pada penelitian ini adalah faktor-faktor penyebab penyebaran penyakit malaria di Indonesia, dimana akan diteliti faktor penyebab penyebaran penyakit malaria $(X)$ terhadap banyaknya presentase penderita penyakit malaria $(Y)$. Adapun pola hubungan antara variabel respon $(Y)$ dengan variabel prediktor $(X)$ dapat dilihat pada Gambar 1 berikut :

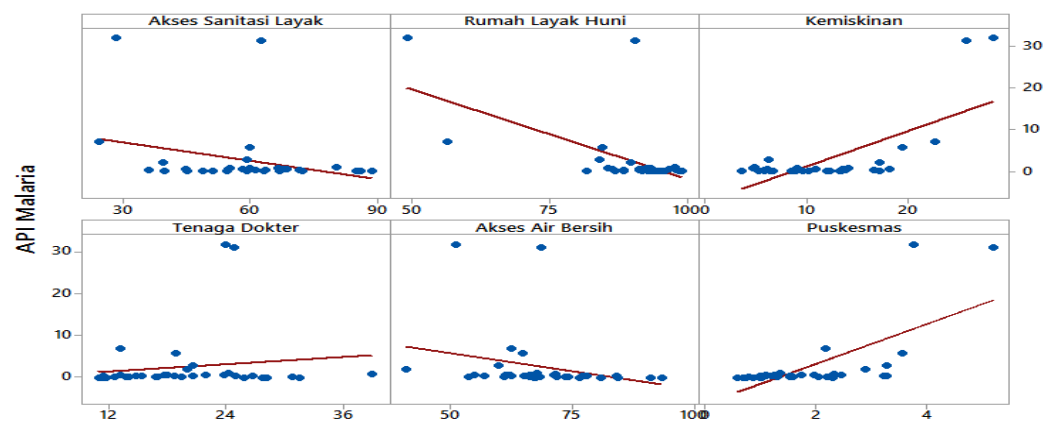

Gambar 1. Scatterplot antara variabel $X$ dan variabel $Y$

Pada Gambar 1 scatterplot di atas, menunjukkan bahwa pola hubungan antara presentase penderita malaria $(Y)$ dengan faktor-faktor penyebab penyakit malaria $(X)$ memiliki pola tidak jelas dan sebaran data menyebar. Pemeriksaan hubungan antar variabel secara statistik dilakukan dengan menggunakan Korelasi Pearson [14].

Pengujian hipotesis korelasi adalah sebagai berikut :

$H_{0}$ : Tidak ada hubungan antar kedua variabel

$H_{1}$ : Terdapat hubungan antar kedua variabel

Koefisien korelasi antar variabel respon dengan variabel prediktor disajikan dalam Tabel 3.

Tabel 3. Koefisien korelasi antar variabel

\begin{tabular}{ccccccc}
\hline Variabel & $Y$ & $X_{1}$ & $X_{2}$ & $X_{3}$ & $X_{4}$ & $X_{5}$ \\
\hline$X_{1}$ & {$[-0,2]$} & & & & & \\
& $(0,08)$ & & & & \\
$X_{2}$ & {$[-0,5]$} & {$[0,71]$} & & & \\
& $(0)^{*}$ & $(0)^{*}$ & & & \\
$X_{3}$ & {$[0,70]$} & {$[-0,44]$} & {$[-0,66]$} & & \\
& $(0)^{*}$ & $(0)^{*}$ & $(0)^{*}$ & & \\
$X_{4}$ & {$[0,13]$} & {$[0,28]$} & {$[0,14]$} & {$[-0,11]$} & \\
& $(0,44)$ & $(0,09)$ & $(0,40)$ & $(0,52)$ & & \\
$X_{5}$ & {$[-0,2]$} & {$[0,70]$} & {$[0,54]$} & {$[-0,43]$} & {$[0,31]$} &
\end{tabular}




\begin{tabular}{ccccccc} 
& $(0,14)$ & $(0)^{*}$ & $(0)^{*}$ & $(0,01)^{*}$ & $(0,06)$ & \\
$X_{6}$ & {$[0,68]$} & {$[-0,39]$} & {$[0,47]$} & {$[0,54]$} & {$[0,24]$} & {$[-0,40]$} \\
& $(0)^{*}$ & $(0,02)^{*}$ & $(0)^{*}$ & $(0)^{*}$ & $(0,15)$ & $(0,01)^{*}$ \\
\hline
\end{tabular}

\section{Ket : [ ] Korelasi Pearson, \\ ( ) $P$-value *) Sig pada $\alpha=5 \%$}

Berdasarkan Tabel 3 diatas, menunjukan bahwa terdapat tiga veriabel yang berkorelasi positif terhadap Annual Parasite Incidence (API) malaria $(Y)$ yaitu presentase rumah layak huni $\left(X_{2}\right)$, variabel presentase penduduk miskin $\left(X_{3}\right)$ dan variabel rasio puskesmas $\left(X_{6}\right)$. Hal ini menunjukan bahwa jika terjadi peningkatan pada variabel presentase rumah layak huni $\left(X_{2}\right)$, variabel presentase penduduk miskin $\left(X_{3}\right)$ dan variabel rasio puskesmas $\left(X_{6}\right)$ akan mengakibatkan semakin tingginya annual parasite incidence (API) malaria $(Y)$ begitu sebaliknya. Sementara itu, variabel presentase akses sanitasi layak $\left(X_{I}\right)$, variabel rasio tenaga dokter $\left(X_{4}\right)$ dan variabel presentase akses air bersih $\left(X_{5}\right)$ memiliki korelasi negarif artinya jika terjadi peningkatan pada variabel tersebut maka akan mengakibatkan penurunan pada Annual Parasite Incidence (API) malaria $(Y)$. Selanjutnya akan untuk memastikan ada atau tidaknya kasus multikolinieritas, dapat dilihat dari nilai Variance Inflation Factors (VIF) dari setiap variabel prediktor [4]. Berikut pada Tabel 4, menunjukan nilai Variance Inflation Factors (VIF) dari masing-masing variabel prediktor yang digunakan dalam penelitian ini.

Tabel 4. Nilai Variance Inflation Factor (VIF)

\begin{tabular}{cc}
\hline Variabel Prediktor & Nilai VIF \\
\hline$X_{1}$ & 3,05 \\
$X_{2}$ & 3,01 \\
$X_{3}$ & 2,20 \\
$X_{4}$ & 1,48 \\
$X_{5}$ & 2,24 \\
$X_{6}$ & 1,99 \\
\hline
\end{tabular}

Berdasarkan Tabel 4, menunjukkan bahwa nilai VIF untuk semua variabel prediktor adalah lebih kecil dari 10 yang artinya tidak terjadi multikolinieritas diantara variabel prediktor. Pengujian data outlier dengan menggunakan metode DFFITS [16].

Pengamatan dinyatakan sebagai outler jika $\mid$ DFFITS $\mid>2 \sqrt{(k+1) / n}=0,907$.

Tabel 5. Pengujian Outlier

\begin{tabular}{lc}
\hline \multicolumn{1}{c}{ Propinsi } & DFFITS \\
\hline Nusa Tenggara Timur & 1,69655 \\
Sulawesi Tenggara & 1,28412 \\
Papua Barat & 6,41416 \\
Papua & 4,55268 \\
\hline
\end{tabular}


Berdasarkan Tabel 5, dapat dilihat bahwa dari 34 Provinsi di Indonesia terdapat empat Propinsi yang dinyatakan sebagai outlier yaitu Propinsi Nusa Tenggara Timur (NTT), Propinsi Sulawesi Tenggara, Propinsi Papua Barat dan Propinsi Papua. Apabila analisis regresi dilakukan dengan menggunakan metode OLS, akan mengakibatkan varians dari penduga parameter besar, sehingga tidak efisien. Oleh karena itu, digunakan regresi quantil untuk menentukan parameter dari faktor-faktor yang mempengaruhi peningkatan presentase penderita penyakit malaria di Indonesia

\section{Estimasi Parameter}

1. Estimasi Parameter dengan Menggunakan Metode Ordinary Least Square (OLS)

Hasil Estimasi metode Ordinary Least Square (OLS) dapat dilihat pada Tabel 6 berikut.

Tabel 6. Estimasi Parameter Ordinary Least Square (OLS)

\begin{tabular}{crrrr}
\hline Parameter & Estimasi & $P$ - Value & $R^{2}$ & MSE \\
\hline$\beta_{0}$ & 2,211 & 0,865 & & \\
$\beta_{1}$ & 0,095 & 0,314 & & \\
$\beta_{2}$ & $-0,255$ & 0,071 & & \\
$\beta_{3}$ & 0,451 & 0,028 & 0,681 & 0,231 \\
$\beta_{4}$ & 0,024 & 0,870 & & \\
$\beta_{5}$ & 0,091 & 0,417 & & \\
$\beta_{6}$ & 3,073 & 0,008 & & \\
\hline
\end{tabular}

Berdasarkan Tabel 6, dapat dilihat bahwa terdapat dua variabel independen yang berpengaruh signifikan terhadap banyaknya Annual Parasite Incidence (API) Malaria di Indonesia yaitu variabel presentase penduduk miskin $\left(X_{3}\right)$ dan variabel rasio puskesmas $\left(X_{6}\right)$. Hasil Estimasi tersebut dapat dimodelkan sebagai berikut :

$$
\hat{Y}=2,211+0,095 X_{1}-0,255 X_{2}+0,451 X_{3}+0,024 X_{4}+0,091 X_{5}+3,073 X_{6}
$$

\section{Estimasi Parameter dengan Metode Regresi Quantil}

Berdasarkan statistika deskriptif menunjukan bahwa terdapat outlier (pencilan) dan tidak semetris pada data. Oleh karena itu, digunakan analisis regresi quantil. Langkah pertama dalam analisis regresi quantil adalah memilih nilai quantil yang ingin diestimasi yaitu quantil $\tau=0.95$.

Tabel 7. Estimasi Parameter Regresi Quantil

\begin{tabular}{ccrrrr}
\hline Quantil & Parameter & Estimasi & $P$-Value & $R^{2}$ & MSE \\
\hline$\beta_{0}$ & 11,934 & 0,031 & & \\
$\beta_{1}$ & 0,170 & 0,000 & \\
$\beta_{2}$ & $-0,394$ & 0,000 & \\
\hline
\end{tabular}




\begin{tabular}{llrrrr}
\hline$Q_{(0,5)}$ & $\beta_{3}$ & 0,407 & 0,000 & 0,83 & 0,182 \\
& $\beta_{4}$ & $-0,275$ & 0,000 & & \\
& $\beta_{5}$ & 0,161 & 0,001 & & \\
& $\beta_{6}$ & 5,704 & 0,000 & & \\
\hline
\end{tabular}

Berdasarkan hasil estimasi pada Tabel 7, Diperoleh model regresi quantil sebagai berikut :

$$
Q_{0,95}(y \mid x)=11,934+0,170 X_{1}-0,3947 X_{2}+0,407 X_{3}-0,275 X_{4}+0,161 X_{5}+5,704 X_{6}
$$

Berdasarkan Tabel 7, dapat diketahui bahwa dengan menggunakan taraf signifikan $(\alpha=5 \%)$ pada quantil $Q_{(0,95}$, maka dapat disimpulkan bahwa variabel yang berpengaruh secara signifikan terhadap peningkatan annual parasite incidence (API) malaria di Indonesia yaitu variabel presentase akses sanitasi layak $\left(X_{1}\right)$, variabel presentase rumah layak huni $\left(X_{2}\right)$, variabel presentase kemiskinan $\left(X_{3}\right)$, variabel rasio banyaknya tenaga dokter $\left(X_{4}\right)$ dan variabel presentase akses air bersih $\left(X_{5}\right)$ serta variabel rasio banyaknya puskesmas $\left(X_{6}\right)$. Pada quantil $Q_{(0,95)}$, diperoleh koefisien determinasi atau $R^{2}$ sebanyak 0,83 . Hal ini menunjukkan bahwa $83 \%$ kasus penyebaran penyakit malaria di Indonesia mampu dijelaskan oleh model, sedangkan sisanya sebesar $17 \%$ dijelaskan oleh peubah lain di luar model.

\section{Pemilihan Model Terbaik}

Setelah mendapatkan model regresi quantil, maka langkah selanjutnya adalah memilih model terbaik dengan melihat nilai koefisien determinasi $\left(R^{2}\right)$ yang paling tinggi dan MSE yang paling rendah [7].

Tabel 8. Koefisien Determinasi $\left(R^{2}\right)$

\begin{tabular}{ccc}
\hline Nilai Quantil & $\begin{array}{c}\text { Koefisien Determinasi } \\
\left(R^{2}\right)\end{array}$ & $M S E$ \\
\hline$Q_{(0,95)}$ & $0,832^{*}$ & $0,182^{*}$ \\
OLS & 0,681 & 0,231 \\
\hline
\end{tabular}

Koefisien Determinasi $\left(R^{2}\right)$ merupakan besaran yang digunakan untuk mengukur kelayakan model regresi dan menunjukan besar kontribusi $X$ terhadap perubahan $Y$. Semakin tinggai nilai $R^{2}$ mendekati 1 semakin baik model regresi yang terbentuk. Sementara itu, Mean Square Error (MSE) adalah suatu metode yang digunakan mengukur tingkat keakuratan suatu model dengan cara menentukan nilai MSE minimum. Berdasarkan Tabel 8. dapat dilihat bahwa pada nilai quantil $Q_{(0,95)}$, memiliki nilai koefisien determinasi $R^{2}$ yaitu sebesar $(0,832)$ lebih besar jika dibandingkan dengan metode Ordinary Least Square (OLS) dengan $R^{2}$ sebesar $(0,681)$. Selain nilai MSE pada quantil $Q_{(0,95)}$ yaitu sebesar $(0,182)$ lebih kecil jika dibandingkan dengan nilai 
MSE pada metode OLS yaitu sebesar $(0,231)$. Hal ini menunjukan bahwa model regresi pada quantil $Q_{(0,95)}$ merupakan model terbaik.

Berdasarkan model terbaik yaitu model estimasi regresi quantil $Q_{(0,95)}$, menunjukan bahwa variabel presentase akses sanitasi layak $\left(X_{l}\right)$ berpengaruh positif dan signifikan terhadap annual parasite incidence (API) malaria. Pada quantil $Q_{(0,95)}$ menunjukan bahwa koefisien variabel persentase akses sanitasi layak $\left(X_{1}\right)$ sebanyak 0,17048 . hal ini berarti bahwa daerah dengan akses sanitasi layak tinggi cenderung memiliki tingkat kerentanan terhadap penyakit malaria. Hal ini tidak sesuai dengan hipotesis yang diharapkan yaitu akses sanitasi layak dapat menurunkan morbiditas penyakit malaria. Ketidaksesuaian hasil ini, diduga disebabkan karena kurang bervariasinya data morbiditas atau API penderita penyakit malaria.

Selanjutnya pada quantil $Q_{(0,95)}$ menunjukan bahwa variabel presentase rumah layak huni $\left(X_{2}\right)$, berpengaruh negatif dan signifikan terhadap API malaria. Koefisien presentase rumah layak huni $\left(X_{2}\right)$ sebanyak minus 0,39447. Artinya jika persentase rumah layak huni di suatu daerah naik sebanyak 1 persen, maka akan menurunkan tingkat annual parasite incidence (API) malaria sebanyak 0,39 per 1000 penduduk. Hal ini sesuai dengan hipotesis yang diharakan bahwa kondisi rumah layak huni dapat mengurangi annual parasite incidence (API) malaria. Kondisi rumah dengan dinding yang terbuat dari kayu memungkinkan lebih banyak lubang untuk masuknya nyamuk. Demikian pula lantai rumah dari tanah menyebabkan kondisi rumah menjadi lembab sehingga menjadi tampat yang ideal bagi nyamuk.

Selanjutnya pada quantil $Q_{(0,95)}$ menunjukan bahwa variabel presentase kemiskinan $\left(X_{3}\right)$ berpengaruh positif dan signifikan terhadap annual parasite incidence (API) malaria. Koefisien presentase kemiskinan $\left(X_{3}\right)$ sebanyak 0,40715. Artinya jika persentase kemiskinan di suatu daerah naik sebanyak 1 persen, maka akan meningkatkan tingkat annual parasite incidence (API) malaria sebanyak 0,40 per 1000 penduduk. Hal ini menunjukan bahwa ada kecenderungan daerah dengan presentase kemiskinan relatif tinggi akan diikuti tingkat annual parasite incidence (API) malaria tinggi pula. Hal ini sesuai dengan hipotesis yang diharpkan bahwa tingkat kemiskinan dapat meningkatkan morbiditas malaria. Hubungan kemiskinan dengan tingkat annual parasite incidence (API) malaria dapat dilihat dari turunan variabel kemiskinan, misalnya penggunaan kelambu dan pekerjaan. Pada banyak penelitian disebutkan bahwa penduduk yang menggunakan kelambu resiko terkena malaria lebih rendah dibanding yang tidak memakai. Demikian pula ada beberapa pekerjaan beresiko seperti nelayan dan pertanian yang lebih rentan terkena malaria dibanding jenis pekerjaan lainnya.

Selanjutnya pada quantil $Q_{(0,95)}$ menunjukan bahwa variabel rasio tenaga dokter $\left(X_{4}\right)$ berpengaruh negatif dan signifikan terhadap annual parasite incidence (API) malaria. Koefisien variabel rasio tenaga dokter $\left(X_{4}\right)$ sebanyak minus 0,27588 . Artinya jika rasio tenaga dokter di suatu daerah naik sebanyak 1 satuan, maka akan menurunkan tingkat annual parasite incidence 
(API) malaria sebanyak 0,27 per 1000 penduduk. Artinya ada kecenderungan daerah dengan rasio tenaga dokter relatif tinggi akan diikuti tingkat annual parasite incidence (API) malaria yang relatif lebih rendah. Hal ini sesuai dengan hipotesis yang diharakan bahwa tenaga kesehatan dapat menurunkan tingkat annual parasite incidence (API) malaria. Hubungan tenaga kesehatan terhadap kerentanan penyakit malaria dapat dijelaskan melalui kegiatan pelayanan kesehatan. Tenaga kesehatan dapat melakukan penyuluhan, penyemprotan, dan pengobatan sehingga dapat mempengaruhi annual parasite incidence (API) malaria di suatu daerah.

Selanjutnya pada quantil $Q_{(0,95)}$ menunjukan bahwa variabel presentase akses air bersih $\left(X_{5}\right)$ berpengaruh positif dan signifikan terhadap annual parasite incidence (API) malaria. Koefisien variabel presentase akses air bersih $\left(X_{5}\right)$ sebanyak 0,16171. Artinya daerah dengan akses air bersih tinggi cenderung memiliki tingkat kerentanan terhadap penyakit malaria. Hal ini tidak sesuai dengan hipotesis yang diharapkan yaitu akses air bersih dapat menurunkan tingkat annual parasite incidence (API) malaria. Ketidaksesuaian hasil ini diduga disebabkan karena kurang bervariasinya data annual parasite incidence (API) malaria. Hal lainya diduga karena akses air bersih pada daerah yang rendah tingkat annual parasite incidence (API) malarianya adalah air leding atau air mengalir lainya. Nyamuk penyebab penyakit malaria biasanya berada pada air tergenang seperti seperti air sumur yang tidak lindungi dan memiliki presentase penggunanya rendah di Indonesia. Sehingga, dampak dari pengaruh air bersih terhadap tingkat annual parasite incidence (API) malaria menjadi tidak bermakna.

Selanjutnya pada quantil $Q_{(0,95)}$ menunjukan bahwa variabel rasio banyaknya puskesmas $\left(X_{6}\right)$ berpengaruh positif dan signifikan terhadap annual parasite incidence (API) malaria. Koefisien rasio banyaknya puskesmas $\left(\mathrm{X}_{6}\right)$ sebanyak 5,7049. Artinya bahwa ada kecendrungan daerah dengan rasio banyaknya puskesmas relatif tinggi, akan diikuti dengan tingkat annual parasite incidence (API) malaria yang relatif tinggi pula. Hal ini tidak sesuai dengan hipotesis yang diharapkan bahwa banyaknya puskesmas dapat menekan tingkat annual parasite incidence (API) malaria. Ketidaksesuaian hubungan ini, diduga disebabkan karena jumlah puskesmas yang banyak tidak menjamin akses ke sarana kesehatan yang lebih baik bagi masyarakat. Hal ini, dimungkinkan pada kawasan Timur Indonesia, sarana puskesmas yang hanya terletak di Ibu Kota Kabupaten dan beberapa Ibu Kota Kecamatan sehingga persebaranya tidak merata. Selain itu, jumlah puskesmas yang banyak namun tidak diikuti dengan pelayanan yang maksimal akan menyebabkan ketimpangan dalam akses sarana kesehatan bagi masyarakat.

\section{Kesimpulan}

Berdasarkan hasil dan pembahasan, maka diperoleh kesimpulan dari penelitian ini adalah sebagai berikut :

1. Hasil estimasi yang diperoleh yaitu metode Regresi Quantil lebih baik jika dibandingkan dengan metode Ordinary Least Square (OLS) pada kasus faktor-faktor yang mempengaruhi penyebaran 
penyakit malaria di Indonesia. Hal ini, ditunjukan dengan nilai $R^{2}$ dari model Regresi Quantil sebesar 0,832 dan nilai MSE yaitu sebesar 0,182. Selain itu, pada model Ordinary Least Square (OLS) diperoleh nilai $R^{2}$ yaitu sebesar 0,681 dan nilai MSE yaitu sebesar 0,231.

2. Faktor-faktor yang mempengaruhi penyebaran penyakit malaria di Indonesia dengan menggunakan model terbaik, pada model regresi quantil dengan $\tau=0,95$ adalah faktor rumah layak huni, faktor penduduk miskin dan faktor tenaga dokter. Oleh karena itu, Pemerintah beserta seluruh elemen masyarakat perlu mengevaluasi dan melakukan proses pencegahan agar terhindar dari penyebaran penyakit malaria.

\section{DAFTAR PUSTAKA}

[1] Badan Pusat Statistika. (2014). Hasil Survei Sosial Ekonomi Nasional Tahun 2014. Jakarta.

[2] Budiantara, I.N. (2011), Penelitian Bidang Regresi Spline Menuju Terwujudnya Penelitian Statistika yang Mandiri dan Berkarakter. Seminar Nasional FMIPA Universitas Pendidikan Ganesha.

[3] Chen, C. dan Wei. (2005). Computational Issues for Quantile Regression. The Indian Journal of Statistics. Vol. 67, hal. 399-417.

[4] Daoud, J. I. (2018). Multicollinearity and Regression Analysis. Journal of Physics: Conference Series, 949(1). https://doi.org/10.1088/1742-6596/949/1/012009

[5] Ghozali, Imam. 2013. Aplikasi analisis Multivariat dengan program SPSS. Edisi ketujuh. Semarang.

[6] Gob, S. C. dan Knight, K. (2009). "Nonstandard Quantile-Regression Inference". Econometric Theory. Vol. 25, hal. 1415-1432 .

[7] Gujarati, D. N. (2004). Basic Econometrics, $4^{\text {th }}$ Edition. New York: McGrahill. Co.

[8] Hardle, W. (1990). Applied Nonparametric Regression. Cambridge University Press. New York.

[9] Hastie, T. J. dan Tibshirani, R. J. (1990). Generalized Additive Models. Chapman and Hall. New York. London.

[10] Kementrian Kesehatan Republik Indonesia. (2014). Profil kesehatan Indonesia, Pusat data dan Informasi Kementrian Kesehatan. Jakarta.

[11] Koenker, R. dan Machado, J. A. F. (1999). Goodness of fit and Related Inference Process for Quantile Regression. Journal of the American statistical Association. Vol. 94, no 448, hal 1296-1310.

[12] Lin W, Zongwu, Li. (2015). Optimal smoothing in nonparametric conditional quantile derivative function estimation. Journal of Econometrics ScienceDirect vol. 188, hal. 502513.

[13] Mirontoneng, A.R, Ismanto, A.Y dan Malara, R. (2014). Analisis faktor-faktor yang berhubungan kejadian malaria pada anak di wilayah kerja PKM Tona kecamatan tahuna 
kabupaten Sangihe. Program Studi Ilmu Keperawatan Fakultas kedokeran Universitas Sam Ratulangi Manado.

[14] Schober, P., \& Schwarte, L. A. (2018). Correlation coefficients: Appropriate use and interpretation. Anesthesia and Analgesia, 126(5), 1763-1768. https://doi.org/ 10.1213/ANE.0000000000002864.

[15] Susilowati, P, A. (2013). Analisis regresi pada prevalensi malaria Provinsi Maluku Utara, Malauku, Papua Barat dan Papua dengan faktor yang mempengaruhinya. Skripsi, Jurusan Statistika Institut Teknologi Sepuluh Nopember.

[16] Umeh, E. U., \& Ojukwu, C. I. (2019). Effects of Influential Outliers in Local Polynomial Techniques (Smoothing

https://doi.org/10.5923/j.ijps.20190801.03. Techniques).8(1),19-22. 